\title{
Quantitative PET imaging of radioligands with slow kinetics in human brain
}

\author{
Sandra M. Sanabria-Bohórquez • Koen Van Laere
}

Received: 2 June 2010 /Accepted: 3 June 2010 /Published online: 25 June 2010

(C) Springer-Verlag 2010

Dear Sir,

We read with interest the commentary by Hirvonen et al. [1] on the quantification of radioligands with slow kinetics. Their critique of our work on the quantification of the type 1 cannabinoid receptor (CB1R) ligand $\left[{ }^{18} \mathrm{~F}\right]$ MK-9470 in the human brain [2] was of particular interest and triggered our response to support the methods that were used in the analysis of the behavior of this novel radioligand. Here we specifically address the vulnerabilities and pitfalls highlighted by Hirvonen et al. and argue that our assumptions can be reasonably justified even in the absence of a "gold standard" for radioligands with slow tissue kinetics.

The general approach for analyzing neuroreceptor PET studies is based on compartmental modeling approaches formulated by Mintun et al. [3]. Even though the mathematical formulation of this model relies on several assumptions (e.g., rate constants are not changing during the PET study and the tracer concentration in the compartments is homogeneous), brain PET imaging analyzed with this approach has been a powerful tool that has enabled the study of neuroreceptor systems in normal and pathological conditions as well as supporting drug development.

The compartmental model formulation is such that the parameters $\left(K_{1}, k_{2}, k_{3}=f_{N D} k_{\text {on }}\left(B_{\text {avail }}-C_{S}\right)\right.$ and $k_{4}=k_{\text {off }}$, where $C_{S}$ is the tracer concentration bound to the receptors

\section{S. M. Sanabria-Bohórquez $(\bowtie)$}

Imaging, Merck Research Laboratories,

Sumneytown Pike WP44D-2,

West Point, PA 19486, USA

e-mail: sandra_sanabria@merck.com

\section{K. Van Laere}

Division of Nuclear Medicine,

University Hospital and K.U. Leuven,

Leuven, Belgium and $f_{N D}$ is the tracer free fraction in tissue [4]) could be related to the biochemical and physiological characteristics of the tracer and the receptor system. The estimation of all five parameters (rate constants and $B_{\text {avail }}$ ) is however only possible when using multiple injection protocols [5-8]. Another approach is to perform a series of studies at different specific activities [9-11] and use an in vivo Scatchard analysis to estimate $B_{\text {avail }}$ and $K_{d}$. It should be noted that very often, when performing single bolus or bolus plus constant infusion (B/I) tracer administration experiments, the individual model parameters cannot be identified (even when the number of parameters is reduced by using high specific activity tracer, so that $\left.k_{\text {on }}\left(B_{\text {avail }}-C_{S}\right) \stackrel{\text { High } S A}{\longrightarrow} k_{\text {on }} B_{\text {avail }}\right)$. The reason that it is not possible to find a unique solution to the individual rate constants is because of the large correlation between parameters and the large coefficients of variation of the estimates. In general, the macro parameters (volume of distribution, binding potential, irreversible uptake rate constant) obtained from the combination of individual rate constants are more stable. As a consequence caution is required when interpreting any estimates of individual rate constants particularly when derived from single tracer injection experiments.

Hirvonen et al. [1] asserted that our assumption that $k_{4}$ is uniform across brain regions is invalid and that $k_{4}$ differs across brain regions in correlation with receptor density. In support of their argument they discussed $\left[{ }^{123} \mathrm{I}\right]$ iomazenil, a SPECT ligand for benzodiazepine receptors that are widely distributed at high density throughout the brain. In nonhuman primates for $\left[{ }^{123} \mathrm{I}\right]$ iomazenil, the in vivo $k_{\text {on }}$ and $k_{\text {off }}$ (estimated using a combination of parameters from in vivo Scatchard analysis [11] and from single bolus tracer studies [12]) were much slower than the in vitro measurements, whereas the ratio of the in vivo rates $k_{\text {on }} / k_{\text {off }}$ was similar to the in vitro measured $K_{d}$ values. 
Hirvonen et al. [1] invoked the re-binding hypothesis to explain the difference between in vivo and in vitro values by proposing that the in vivo dissociation rate constant is dependent on the density of receptors available for binding. However, it can be argued that the large differences in radioligand behavior and characteristics are expected because of the profound differences between in vivo and in vitro imaging techniques used to generate the data (see discussion and references in Inoue et al. [13]). Furthermore, in the $\left[{ }^{123} I\right]$ iomazenil studies [11], the in vivo $k_{4}$ estimates were actually similar between regions with different $B_{\text {avail }}$ ([11], Table 4) and were reported to be "virtually identical across regions" when using a bolus tracer injection protocol ([12], Table 3). These data and interpretation are supported by the $\left[{ }^{123} I\right]$ iomazenil $k_{4}$ values estimated by Millet et al. [14] using a multi-injection protocol that were similar throughout the human brain with the exception of the $k_{4}$ value in the pons which was $\sim 65 \%$ smaller relative to cortex and cerebellum regions. This difference was probably methodological and due to the small displacement observed during the cold tracer injection segment in this region which compromised accurate estimation of $k_{4}$. In addition to these data from SPECT, PET studies using a multi-injection protocol with $\left[{ }^{11} \mathrm{C}\right]$ flumazenil have also shown that $k_{4}$ is not dependent on $B_{\text {avail }}$ and that it is uniform across regions in the human brain [6]. Moreover, the recent work of Vandehey et al. [8] suggests that $k_{4}$ is also uniform across all brain regions for the $\mathrm{D} 2 / \mathrm{D} 3$ radioligands $\left[{ }^{18} \mathrm{~F}\right]$ fallypride and $\left[{ }^{11} \mathrm{C}\right]$ FLB 457. This is an important observation since any difference in $k_{4}$ across regions of high and low $B_{\text {avail }}$ should be exaggerated as D2 receptor density in the postmortem human brain has been shown to be $>15$-fold lower in extrastriatal structures than in striatal structures [15].

The strategy of simultaneously fitting data from several brain regions while coupling parameters that are expected to be similar across the brain has been used by many investigators to increase the identifiability of the kinetic parameters. In the specific case of $k_{4}$, several examples can be found in the literature for a variety of PET ligands for different targets where tracer binding quantification has been made more robust by assuming a global $k_{4}$ value $[5,14,16-$ 21]. We cannot therefore find any empirical or theoretical reason that would argue against our simplifying assumption that $\left[{ }^{18} \mathrm{~F}\right] \mathrm{MK}-9470 k_{4}$ values are uniform throughout the human brain.

Hirvonen et al. [1] appear to have overlooked that our analyses of $\left[{ }^{18} \mathrm{~F}\right] \mathrm{MK}-9470$ made use of the known pharmacological characteristics of $\left[{ }^{18} \mathrm{~F}\right] \mathrm{MK}-9470$ to determine the tracer modeling approach and to quantify the tracer-specific binding in the human brain. Indeed, despite the brain kinetics of $\left[{ }^{18} \mathrm{~F}\right] \mathrm{MK}-9470$ being relatively slow, studies in nonhuman primates have clearly shown that the radioligand can be displaced from the receptors [22] supporting the use of a reversible binding model. In our studies, the use of a global $k_{4}$ estimated using simultaneous fittings of the brain data to a two-compartment model provided reliable estimates of $V_{T}$, $V_{N D} k_{3}$, and $k_{4}$. Furthermore, the results from our early studies using this reversible approach showed that the scan time could be reduced to $180 \mathrm{~min}$ ([2], Fig. 4) improving the practicality of data acquisition during the conduct of the imaging studies. Whilst we have described $\left[{ }^{18} \mathrm{~F}\right] \mathrm{MK}-9470$ tracer kinetics using a reversible model, the tracer clearance during the initial 180-min interval required to estimate the tracer binding to the receptors is negligible ([2], Fig. 1), consistent with the small $k_{4}$ value $\left(0.0041 \pm 0.0010 \mathrm{~min}^{-1}, n=\right.$ 6 studies). As a result of the small $k_{4}$ the use of an irreversible model may also be justified even though the tracer binding is known to be reversible. This is analogous to the way $\left[{ }^{18} \mathrm{~F}\right] \mathrm{FDG}$ brain data are handled, where although it is possible to measure a small $k_{4}$ value, the net irreversible uptake rate constant $K_{i}$ is the parameter generally used to estimate the glucose consumption throughout the brain [23]. We argue that such a macro parameter approach is also applicable for receptor binding studies and that $\left[{ }^{18} \mathrm{~F}\right] \mathrm{MK}$ 9470 can also be simply analyzed in this way. We therefore used $K_{i}$ and the fractional uptake rate (FUR) as indexes of tracer binding to $\mathrm{CB} 1$ receptors. A clear linear relationship between the reversible and irreversible parameters ([2], Fig. 7) demonstrated that $K_{i}$ and FUR indeed convey receptor availability information. Since the integrals of the plasma curve $(0-180 \mathrm{~min})$ and the brain curves $(120-180 \mathrm{~min})$ are used for the calculation of FUR values, a reduction in the bias from noise in the measurements is also observed. The use of a simple irreversible model to analyze $\left[{ }^{18} \mathrm{~F}\right] \mathrm{MK}-9470$ significantly improved the test-retest reproducibility of tracer binding indexes (see Table 3 in [2] for a comparison of reproducibility for all studied parameters including brain uptake as discussed in isolation by Hirvonen et al.).

We therefore can conclude that the kinetics of radioligands that slowly wash out from the brain can successfully be characterized with macro parameters that convey receptor availability information. Therefore, we reiterate that for the CB1R inverse agonist $\left[{ }^{18} \mathrm{~F}\right] \mathrm{MK}-9470$-specific binding in the brain can be quantified accurately using a simplified method and that imaging of the CB1 receptors in the human brain using this radioligand can reliably support the development of potential therapeutics.

Conflicts of interest SMSB is an employee of Merck Inc., Co.

\section{References}

1. Hirvonen J, Terry GE, Halldin C, Pike VW, Innis RB. Approaches to quantify radioligands that wash out slowly from target organs. Eur J Nucl Med Mol Imaging 2010;37:917-9. 
2. Sanabria-Bohórquez SM, Hamill TG, Goffin K, De Lepeleire I, Bormans G, Burns HD, et al. Kinetic analysis of the cannabinoid1 receptor PET tracer [(18)F]MK-9470 in human brain. Eur J Nucl Med Mol Imaging 2010;37:920-33.

3. Mintun MA, Raichle ME, Kilbourn MR, Wooten GF, Welch MJ. A quantitative model for the in vivo assessment of drug binding sites with positron emission tomography. Ann Neurol 1984;15:217-27.

4. Innis RB, Cunningham VJ, Delforge J, Fujita M, Gjedde A, Gunn $\mathrm{RN}$, et al. Consensus nomenclature for in vivo imaging of reversibly binding radioligands. J Cereb Blood Flow Metab 2007;27:1533-9.

5. Christian BT, Narayanan T, Shi B, Morris ED, Mantil J, Mukherjee J. Measuring the in vivo binding parameters of [18F]-fallypride in monkeys using a PET multiple-injection protocol. J Cereb Blood Flow Metab 2004;24:309-22.

6. Delforge J, Pappata S, Millet P, Samson Y, Bendriem B, Jobert A, et al. Quantification of benzodiazepine receptors in human brain using PET, [11C]flumazenil, and a single-experiment protocol. J Cereb Blood Flow Metab 1995;15:284-300.

7. Sanabria-Bohórquez SM, Labar D, Levêque P, Bol A, De Volder AG, Michel C, et al. [11C]flumazenil metabolite measurement in plasma is not necessary for accurate brain benzodiazepine receptor quantification. Eur J Nucl Med 2000;27:1674-83.

8. Vandehey NT, Moirano JM, Converse AK, Holden JE, Mukherjee J, Murali D, et al. High-affinity dopamine D2/D3 PET radioligands 18F-fallypride and 11C-FLB457: a comparison of kinetics in extrastriatal regions using a multiple-injection protocol. J Cereb Blood Flow Metab 2010;30:994-1007.

9. Ginovart N, Wilson AA, Hussey D, Houle S, Kapur S. D2receptor upregulation is dependent upon temporal course of D2occupancy: a longitudinal [11C]-raclopride PET study in cats. Neuropsychopharmacology 2009;34:662-71.

10. Sossi V, Holden JE, Topping GJ, Camborde ML, Kornelsen RA, McCormick SE, et al. In vivo measurement of density and affinity of the monoamine vesicular transporter in a unilateral 6hydroxydopamine rat model of PD. J Cereb Blood Flow Metab 2007;27:1407-15.

11. Laruelle M, Abi-Dargham A, al-Tikriti MS, Baldwin RM, ZeaPonce Y, Zoghbi SS, et al. SPECT quantification of [123I] iomazenil binding to benzodiazepine receptors in nonhuman primates: II. Equilibrium analysis of constant infusion experiments and correlation with in vitro parameters. J Cereb Blood Flow Metab 1994;14:453-65.

12. Laruelle M, Baldwin RM, Rattner Z, al-Tikriti MS, Zea-Ponce Y, Zoghbi SS, et al. SPECT quantification of [123I]iomazenil binding to benzodiazepine receptors in nonhuman primates: I. Kinetic modeling of single bolus experiments. J Cereb Blood Flow Metab 1994;14:439-52.
13. Inoue O, Kobayashi K, Gee A. Changes in apparent rates of receptor binding in the intact brain in relation to the heterogeneity of reaction environments. Crit Rev Neurobiol 1999;13:199-225.

14. Millet P, Graf C, Moulin M, Ibáñez V. SPECT quantification of benzodiazepine receptor concentration using a dual-ligand approach. J Nucl Med 2006;47:783-92.

15. Kessler RM, Whetsell WO, Ansari MS, Votaw JR, de Paulis T, Clanton JA, et al. Identification of extrastriatal dopamine D2 receptors in post mortem human brain with [125I]epidepride. Brain Res 1993;609:237-43.

16. Buck A, Westera G, vonSchulthess GK, Burger C. Modeling alternatives for cerebral carbon-11-iomazenil kinetics. J Nucl Med 1996;37:699-705.

17. Bottlaender M, Valette H, Delforge J, Saba W, Guenther I, Curet O, et al. In vivo quantification of monoamine oxidase $\mathrm{A}$ in baboon brain: a PET study using [(11)C]befloxatone and the multi-injection approach. J Cereb Blood Flow Metab 2010;30:792-800.

18. Cunningham VJ, Ashworth S, Rabiner EA, Plisson C, Searle GE, Gunn RN, et al. Kinetic analysis of [11C]GSK189254, a novel radioligand for the $\mathrm{H} 3$ receptor in humans using positron emission tomography (PET). Neuroimage. Neuroreceptor Mapping 2008, The Seventh International Symposium on Functional Neuroreceptor Mapping of Living Brain, 2008. 41: T14.

19. Cunningham VJ, Rabiner EA, Matthews JC, Gunn RN, Zamuner $\mathrm{S}$, Gee AD. Kinetic analysis of neuroreceptor binding using PET. International Congress Series Quantitation in Biomedical Imaging with PET and MRI. Proceedings of the International Workshop on Quantitation in Biomedical Imaging with PET and MRI, 2004. 1265: 12-24.

20. Gallezot JD, Bottlaender MA, Delforge J, Valette H, Saba W, Dollé F, et al. Quantification of cerebral nicotinic acetylcholine receptors by PET using 2-[18F]fluoro-A-85380 and the multiinjection approach. J Cereb Blood Flow Metab 2008;28:172-89.

21. Ginovart N, Wilson AA, Meyer JH, Hussey D, Houle S. Positron emission tomography quantification of [(11)C]-DASB binding to the human serotonin transporter: modeling strategies. J Cereb Blood Flow Metab 2001;21:1342-53.

22. Burns HD, Van Laere K, Sanabria-Bohórquez S, Hamill TG, Bormans G, Eng WS, et al. [18F]MK-9470, a positron emission tomography (PET) tracer for in vivo human PET brain imaging of the cannabinoid-1 receptor. Proc Natl Acad Sci U S A 2007;104:9800-5.

23. Hong YT, Fryer TD. Kinetic modelling using basis functions derived from two-tissue compartmental models with a plasma input function: general principle and application to $[18 \mathrm{~F}]$ fluorodeoxyglucose positron emission tomography. Neuroimage 2010;51:164-72. 